\title{
A DESTRUIÇÃO DO IRREAL: DE GAUTIER A ALUISIO AZEVEDO
}

\author{
Maria Cecilia de Moraes Pinto
}

Um dos traços mais significativos da subliteratura é sua fidelidade a um Modelo bem sucedido que se atualiza em uma série infindável de variantes substancialmente iguais. O leitor experimenta assim o conforto do mesmo no ilusório e atraente disfarce do outro. Em alguns casos, o subliterário serve-se de obras particulares que ajusta a seu arquétipo genérico com maiores ou menores perdas e os acréscimos necessários. A degradação do original vai então registrar os limites da mistura de gêneros e tornar manifestas estruturas elementares.

Considerações dessa ordem surgem quase espontaneamente diante de um romance de Aluísio Azevedo, esquecido pela crítica: $A$ Mortalha de Alzira. Em 1891, a Gazeta de Notícias publicava-o em seu folhetim. Sob o pseudônimo de Vítor Leal, mais uma vez cedia Aluísio aos imperativos econômicos da profissionalização literária. Juntando ingredientes de segura aceitação popular e duvidoso gosto artístico, A Mortalha teve boa acolhida, transformando-se em livro (1894). Era quase um pastiche como sugeria a nota ao leitor. Tratava-se, com efeito, de "vasto jardim artificial, feito de frias, perpétuas e secas margaridas" impregnado "pelo aroma de uma flor, uma só, que é a sua alma - "La Morte Amoureuse" de Théophile Gautier. (1)

O reconhecimento da fonte inspiradora ajuda a equacionar 0 problema a que me referi, pois o texto francês é um conto fantástico romântico que Aluísio converte à forma jornaléstica do romance em (1961), p. 1 .

(1) - Aluísio Azevedo. A Mortalha de Alzira. São Paulo, Martins Língua e Literatura, (14), 1985. 
capítulos (2). A comparação das duas narrativas entre si tende a mostrar, por outro lado, o que caracteriza os gêneros a que pertencem e como a indústria literária da produção em larga escala banaliza a emoção, a força sugestiva de um texto superior

Escrevendo sobre Théophile Gautier, Joan-Bellemin-Noël propõe que se chamem respectivamente de fantasmagórico e fantasmático ao modo de contar o acontecimento fantástico e ao que, nesse acontecimento, se aproxima da estrutura da fantasia, o termo usado aqui no sentido psicanalítico. (3) O fantásmatico situa-se, pois e sobretudo, a nível da fabulação e é através dela que se manifesta em um conteúdo cujas partes se organizam à maneira do sonho, do devaneio, do delírio, como tal devendo ser analisado.

LaMorte amoureuse e A Mortalha de Alzira contam a história de um padre apaixonado por uma mulher que, depois de morta, vem pertubar seus sonhos. No texto de Gautier, Romuald, o narrador, conhece-a no dia de sua ordenação e perde-a de vista quado assume a direção de sua primeira paróquia. Certa noite, é chamado para atender uma agonizante. Trata-se de Clarimonde cuja lembrança tanto o perturba. Encontra-a morta. No seu desespero, beija-a, devolvendo-lhe a vida por alguns instantes. De volta a casa, passa a viver de modo estranho. De dia, exerce seu ministério; de noite, Clarimonde arrebata-o para um mundo de aventuras, riquezas e orgias. Um confrade, Sérapion, adverte-o de que a cortesã morta era um vampiro. Efetivamente, o caráter monstruoso de sanguessuga vai-se revelando aos poucos mas, embora impressionado, Romuald não tem coragem de recusar à amada a substância que a mantém viva. A situação é resolvida por Sérapion que, no cemitério, mostra-lhe o cadáver de Clarimonde. A aspersão com água benta pulveriza o corpo e livra Romuald de seus pesadelos (sonhos?).

$O$ texto brasileiro, narrado em terceira pessoa, segue de perto a matriz estrangeira. Ângelo, o protagonista, é um enjeitado que frei Ozéas criou a fim de expiar pecado de juventude pela consagração dessa alma pura ao serviço divino. No dia de sua primeira miss, o jovem vê Alzira, mulher célebre em Paris pelos costumes levianos.

(2) - Insinua-se aqui uma discussão paralela sobre os critérios de classificação dos gêneros. Para contorná-la, lembrarei apenas que, segundo Todorov, "les genres existent à des niveaux de généralités différents et que le contenu de cette notion se définit par le point de vue qu"on choisit." In troduction à la littérature fantastique. Paris, Seuil (1970), p. 9).

(3) - "Notes sur le Fantastique (textes de Théophile Gautier)" in Littérature $\mathrm{n}^{0} 8$. Paris, Larousse (déc. 1972), p. 4, 6. Quanto a fantasia, o francês diz fantasme e o alemão phantasien (cf. J. Laplanche e J-B Pontalis, Vocabulaire de la Psychanalyse, 6e. éd. Paris, PUF, 1978). 
Sente-se mal, sem conseguir explicar a razão. Em um providenciai e fortuito encontro, o sacerdote percebe que está amando. Ozéas, entretanto, afasta-o para Montelli onde Alzira vai procurá-lo. Depois de recusar o amor impossível, Ângelo cai em profunda melancolia até que the pedem para ir ver alguém à morte. Repetem-se as cenas de La Morte amoureuse: beijo, ressureição, sonhos, vida dupla. Só que Ângelo é assistido, sem que o saiba, pelo dr. Cobalt, amigo de Alzira e interessado em casos de "histeria" Por outro lado, embora esteja a esgotá-lo, Alzira a rigor não é, como Clarimonde, uma estrige. Ozéas conduz seu discípulo ao túmulo da morta para convencê-lo de que está arriscando sua salvação por um cadáver. Ângelo desmaia e Ozéas sai à procura de água. Quando o padre volta a si, tem uma espécie de visão na qual Alzira, bela como sempre, dizlhe adeus (em Gautier, a despedida ocorre no sonho). $O$ retorno de Ozéas desencadeia a rebelião: Ângelo mata-o e suicida-se logo a seguir

Sem pretender explorar a fundo os caminhos da interpretação psicanalítica, seria possível identificar, no romance de Ângelo e $\mathrm{Al}$ zira, as linhas gerais da situação fantasmática que Bellemin-Noël detecta no conto de Théophile Gautier. A jovem vítima de uma mulher de além-túmulo revive, na sua relação com ela, simbolicamente Mãe possuída e possuidora, o medo da castração. À figura feminina que retorna para tirar a vitalidade do filho, do desprotegido, seja pelos excessos sexuais, seja pelo roubo de sangue, opõe-se o Pai cuja intervenção elimina a angústia. Esse Pai, violando a sepultura (= agressão sexual) restitui ao filho o controle da situação. É bem verdade que, no escritor brasileiro, a imagem paterna desdobra-se na pessoa do médico cuja intromissão, porém, não chega a ser relevante, salvo no plano dos procedimentos narrativos. Vale também lembrar que, se os dois protagonistas conseguem superar o impasse do ciclo infernal que lhes cinde a personalidade, não o fazem da mesma maneira. Entre a "fusão destruidora" e a "radical separação", Romuald opta por esta (mas fica-lhe a lembrança instigadora do relato) enquanto Ângelo busca reaver, com a autodestruição, o bem perdido e ainda desejado. Diz ele, antes de lançar-se ao abismo:

“- Não é a morte, é o sono eterno! ( . .)

Eu quero sonhar!.. 
A visão sucinta dessa possibilidade de leitura interpreetativa do fantástico denuncia um dos escolhos da abordagem psicanalítica em literatura: revelar "universais" da linguagem do inconsciente sem atingir o âmago da questão literáría. $\mathrm{Na}$ verdade, ainda que não se conceba desprezar a idéia ou conteúdo, sua análise isolada não informa sobre os elementos que fizeram da obra aquilo que ela é. Convém, portanto, centrar o estudo nas técnicas que verbalizam literariamente a fantasia, fantasia que não se perderá de vista por constituir parte integrante do processo. E esse fantasmagórico, presente na narrativa francesa, que se deteriora com Aluísio.

A primeira e mais evidente causa está na alteração da forma de publicação. Como romance-folhetim, o conto ampliou-se e sofreu cortes em capítulos. Foram criados novos personagens, introduziram-se descrições digressões; e por outro lado, o sistema do "continua no próximo número" destinado a prender o leitor (e vender o jornal), suscita o oparecimento do suspense que desencadeia e controla a emoção até o desenlace definitivo.

O maior número de personagens (em Gautier, há apenas quatro: Romuald, Sérapion, Clarimonde e o ouvinte conhecido apenas por um "frère" bastante vago) favorece a irrupção de episódios paralelos (duelo entre amantes de Alzira, o caso da viúva do morgado de Thevenet, o baile dos espectros etc) de escasso interesse para o andamento da ação. Nos lances que mais chamam a atenção, inclui-se aquele que envolve o dr. Cobalt. À semelhança do figurino naturalista de zola, Aluísio leva seu cientista a fornecer uma explicação racional para o caso de Ângelo, que seria verdadeiro exemplo de manifestação histérica. O médico materialista desaparece, contudo, no final, seu último diagnóstico fica no ar A presença desse personagem traz à baila o anticlericalismo e a crítica (ao gosto de Eça) do celibato clerical, endossada pelo protagonista, que reforça, aliás, uma idéia disseminada ao longo do livro. Perdida a mulher amada, vem a denúncia:

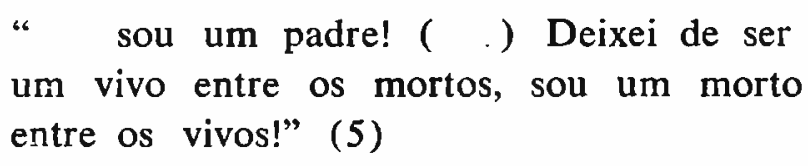

Ocorre também a multiplicação dos espaços. A concentração da ação em Gautier pede alguns poucos cenários escassamente descritos: a cela do seminarista em $\mathrm{S}$. a casa paroquial em $\mathrm{C}^{* * *}$ (observe-se a ausência de topônimos), o palácio de Veneza onde vi-

(5) - Mortalha, p. 252. 
vem os amantes, o cemitério. Em Aluísio, esses quadros fundamentais permanecem, mas desdobrados e enriquecidos. S. é Paris da Regência de Philippe d'Orléans e do reinado de Luís XV A notação exótica e histórica induz à descrição de vários locais $\mathrm{e}$ completa-se pela caracterização de grupos humanos (mas estamos muito longe de $O$ Cortiço!) e comentários sobre os costumes da época, a Revolução vindoura, o que não evita anacronismos. Montelli, por sua vez, é $\mathrm{C}^{* * *}$ um tanto ampliada. Quanto ao sonho-fantasia, ele é ocupado por espaços diferentes: o mundo dos mortos onde dançam os espectros; a caverna das riquezas; uma cidade que tem gôndolas e na qual, após o passeio tradicional, Ângelo e Alzira participam de uma orgia sanguinária.

Funciona assim, a "regra das três multiplicidades" (6) (ação, tempo e espaço), adornada pelo macabro, e substituindo a sobriedade do texto de La Morte amoureuse que confina o estranho à estranheza de uma única variável: o amor da mulher devoradora.

Outro tipo de dilatação são as digressões que aparecem no capítulo dedicado a uma imitação do Cântico dos Cânticos e nas citações do livro de Jó.

Já o suspense instaura-se nos finais de capítulo que indicam um movimento projetado (cap. VII — anúncio do comparecimento de Alzira à missa de Ângelo) ou em curso (cap. XV Ângelo saindo para encontrar Alzira); uma mudança nos rumos da ação (cap. XIII da segunda parte - Ozéas teme a excursão ao cemitério); um relato (cap. X da segunda parte - vai ser narrada a luta de Ângelo com a própria sombra).

La Morte amoureuse não tem pausas. Pontilham-na apenas observaçōes de Romuald com o fito de preparar o espírito de seu interlocutor:

"Ce sont des événements si étranges que je ne puis croire qu'ils me soient arrivés"

- condenar o discurso:

"Je ne vous retiendrai pas plus longtemps sur ces défaites et ces victoires intérieures toujours suivies de rechutes plus

(6) - Jacques Goimardy, "Quelques structures formelles du roman populaire" in Europe $\mathrm{n}^{0} 542$, Le Roman feuilleton. Paris, Editeurs Français Réunis, (juin 1974), p. 22.

(7) - Théophile Gautier, Nouvelles, nouvelle édition. Paris, Biblin théque Charpentier-Eugène Fasquelle éd. (1898), p. 261. 
profondes, et je passerai sur-le-champ à une circonstance décisive." (8)

- reiterar, em conclusão, afirmações iniciais:

"Ne regardez jamais une femme. et marchez toujours les yeux fixés en terre. car, si chaste et si calme que vous soyez, il suffit d'une minute pour vous faire perdre l'éternité." (9)

Percebe-se que o distanciamento crítico de Romuald, em relação aos fatos passados (10), lhe confere autenticidade. Foram vividos pelo narrador que, agora, pode serenamenette encará-los. Se, apesar de tudo, aos 66 anos, ainda lhe sobram dúvidas quanto à realidade de suas experiências - "J'ai mené en rêve toutes les nuits (Dieu veuille que ce soit un rêve! une vie de damné" (11) é porque o enigma permanece.

Já o recurso a um narrador em terceira pessoa se permite, no livro do Aluísio, a mobilidade da onisciêncịa, tão desejável no folhetim, retira à história de Ângelo o caráter anormal. O narador, que censura os desregramentos da época e solidariza-se nesse ponto com o dr. Cobalt, implicitamente também encara os fenômenos de que Ângelo é vítima como pura curiosidade científica. Por isso, já assinalava Araripe Júnior que à Mortalha faltava "a nota do assombro; e é justamente dessa nota que resulta o sabor que nós ainda hoje eencontramos nos contos fantásticos de Hoffmann e nos romances de Ana de Radcliffe"' (12.

Esse o segundo motivo pelo qual Aluísio deforma a contrução do fantástico. Ângelo, profetiza Cobalt (e junto dele o narradorautor manipula seus fantoches), terá de render-se ao seu destino de homem, quando a natureza "indefectível nas suas leis, o chamar friamente à verdade das cousas" (13). A inquietação dilui-se e o caso é reduzido a mero "fenômeno fisiológico" Instauram-se assim dois planos: o do protagonista, onde o irreal casa-se ao real e o do narrador, compartilhado por Cobalt e mesmo Ozéas. Por razões diferentes, os três diagnosticam, direta ou indiretamente, uma doença. A partir daí, a leitura tem de ser dupla. Como Romuald, que ignora se Clarimonde é anjo ou demônio, o amante de Alzira confude-a com

(8) - Id., ibid., p. 275.

(9) - Id., ibid., p. 295.

(10) - No plano fantasmático, o narrador teria, segundo BelleminNoël, a função de censura.

(11) - La Morte amoureuse, p. 261.

(12) - Obra crítica de Araripe Júnior, v. III. Rio, MEC (1963), p. 173.

(13) - Mortalha, p. 46. 
a Virgem Maria. Mas, na organização narrativa, tal hesitação não passa de produto de uma mente doentia, enfraquecida. E o ser ambíguo bom/mau que, em Gautier, suscita amor e horror, encarna aqui um dos lados do conflito entre pecado e virtude, questão mal colocada pela Igreja ao exigir a castidade impossível.

Do mesmo modo, uma expressão corriqueira como "mais forte que a morte" adquire na boca de Clarimonde um sentido literal extremamente forte. O vampiro venceu, por algum tempo, a morte e retorna ao convívio dos seres humanos:

“ et pourtant me voici, car l'amour est plus fort que la mort, et il finira par la vaincre." (14)

Essa aspiração à eternidade também é comunicada, em $A M o r-$ talha de Alzira, na frase que intitula o capítulo VI da segunda parte. Contudo, apenas Ângelo pode dar-lhe essa interpretação. Na verdade, seu diálogo com Alzira, quando esta lhe diz que vem "de muito longe (. .) do mundo dos mortos, mundo de sombras e de sonhos!. " (15) - está marcado, pelo narrador, com a rubrica: imaginação desvairada, não acreditar.

Com Aluísio, o mistério resume-se, portanto, a algumas portas fechadas, a personagens que chegam de surpresa. É o mistério do suspense e não o mistério que leva a duvidar daquilo que os olhos vêem a mente só aceita com relutância. Desperdiçam-se mesmo efeitos preciosos como os que Théophile Gautier emprega para indicar a aproximação de Clarimonde. Quando Romuald instala-se em C***, a solidão, o silêncio e a obscuridade, sempre propício à angústia das situações novas, fazem-no perceber ou crer que percebe um vulto de mulher no jardim, com os olhos verdes a brilharem por entre a folhagem. Chega perto e, no espaço cercado por muros altos, encontra pegadas quase infantis. (16) Em um crescendo, Romuald experimenta, durante um ano, a aridez que precede as revelações e é, em meio a seu desamparo, que ocorre o episódio da enferma que manda buscar um padre. A descrição da cavalgada pela floresta, dos cavalos pretos, do escudeiro cujo grito "n'avait rien d'humain" (17) - prepara a cena altamente dramática em que ele contempla a amada morta .

No texto brasileiro, toda essa progressão se traduz por uma fase depressiva de Ângelo, sem marcas de sobrenatural. Ele sofre

(14) - La Morte amoureuse, p. 284.

(15) - Mortalha, p. 163.

(16) - La Morte amoureuse, p. 274.

(17) - Ibidem, p. 276. 
de um "mal secreto" Chega a noite de tempestade em que dois homens lhe pedem para ir dar a extrema-unção a uma moribunda. O que, em Gautier, tomara quase duas páginas condensa-se agora em dois parágrafos onde Aluísio fala de cavaleiros negros semelhantes a fantasmas e de cavalos apavorados. Mas a tensão emotiva gasta-se no longo diálogo anterior à partida .

Em suma, ao inspirar-se em Gautier, o autor brasileiro não retém o essencial que lhe escapa na expansão desordenada de um dis. curso entrecortado, na frieza explicativa, no excesso de macabro. Desfaz-se o fantástico em mera exploração de fatos bizarros e romanescos.

As transferências de um gênero a outro não implicam forçosamente grandes danos. Teoricamente as possibilidades combinatórias são infinitas. Sujeitos que são às necessidades históricas e literárias, os gêneros desaparecem, ressurgem, mesclam-se. $O$ folhetim, no século XIX, pôde assimilar perfeitamente o romance histórico e o romance de costumes. Contudo, a fantástica, ou seja, a narrativa, pelo menos na tentativa de Aluísio, parece acomodar-se mal às normas da publicação periódica. Seria de se perguntar se não há entre elas uma incompatibilidade visceral.

Fundado na oposição entre a realidade e a irrealidade ou sobrenatural, o fantástico sobrevive em instável equilíbrio. A inquietação gerada por acontecimentos aparentemente inexplicáveis quase nunce se prolonga. Em seu célebre "Das Unheimliche", Freud (18) distingue a "inquietante estranheza" sentida na vida cotidiana, por exemplo diante da repetição inabitual de um incidente ou de uma série de incidentes, da mesma sensação provocada pelo texto literário. Com efeito, se o escritor dispōe de meios para reforçar o estranho, ele deve, em contrapartida, convencer seu leitor. E convencer de maneira a não consentir que este tenha tempo para racionalizar suas emoções, ou seja, as emoções que lhe foram transmitidas. Todorov, de certo modo, tem razão ao afirmar que o fantástico não resiste a uma segunda leitura. Quando muito, conserva uma aura poética, como acontece com La Morte amoureuse. Por isso, toda expansão oferece o risco de dissolver logicamente aquela hesitação básica que o leitor precisa conhecer. O fantástico (e nisso, ele tem algo da poesia lírica) se realiza melhor em textos mais curtos, em formas concisas que tendem a evitar grandes desdobramentos de tempo, lugar e ação. O conto lhe convém sobremaneira e seguramente o ro-

(18) - In Essais de psychanalyse appliquée. Paris, Gallimard, (1956). p. 163-210. (trad. de Marie Bonaparte et Mme. E. Marty). 
mance-folhetim, ao alongar-se por dias, semanas, meses, prejudica 0 clima de incerteza que lhe é peculiar

Por conseguinte, ao optar por uma forma pouco econômica, Aluísio sacrificava a priori o tom característico da obra que o motivara. Entretanto, também o elemento naturalista desempenha, nesse sentido, um papel negativo. A imitação praticada revela adaptação não só a um gênero, rigidamente codificado, como ainda a um movimento literário. Em que pese nosso proverbial atraso em relação às vanguardas européias, o Brasil de fins do século XIX não mais se pautava pelas normas do Romantismo. Daí o toque cientifízante, a introdução do personagem Cobalt, esse espectador enigmático, frio. É a pincelada de modernidade naturalista, a adequação do antigo ao novo. Por essa razão, dizer que $A$ Mortalha representa a permanência da sensibilidade romântica denigre o que há de legítimo no romantismo de La Morte amoureuse, sem chegar a esclarecer o texto de Aluísio Azevedo. Fusão mal feita do ontem e do hoje, ele ilustra o tipo de trabalho apressado, desprovido de maiores preocupações estilísticas ou estruturais (cf. os desaparecimentos injustificados, uma repentina alusão a milagres de Ângelo, etc), construído a partir de outro não recriado, mas encaixado a um molde onde se destaca o indispensável apelo à moda contemporânea .

De qualquer forma, ao destruir o irreal do fantástico, Aluísio recusa o real oculto na fantasia. O desvendamento rasteiro da interpretação científica cria um realismo de fachada que se conjuga à gratuita necrofilia do romantismo mais epidérmico. Em outras palavras, desprezado o irreal crível envereda-se pelo real incrível. E, finalmente, não se levam em conta nem as exigências do fantástico como gênero, nem as do realismo como estética. Comparada aos grandes romances, $O$ Cortiço, $O$ Mulato, A Casa de Pensão, essa Mortalha não evidencia a face encoberta de um Aluísio romântico, e sim, a caricatura literária, o melodrama que atende a uma certa expectativa de novidade, mas sacrifica, em benefício do previsível, a riqueza da invenção. 